\title{
Identification of Synchronized Role of Transcription Factors, Genes, and Enzymes in Arabidopsis thaliana under Four Abiotic Stress Responsive Pathways
}

\author{
Samsad Razzaque, ${ }^{1,2}$ Rabab Mahdi, ${ }^{1}$ and Aparna Islam ${ }^{1}$ \\ ${ }^{1}$ Biotechnology Programme, Department of Mathematics and Natural Sciences, BRAC University, Dhaka 1212, Bangladesh \\ ${ }^{2}$ Plant Biotechnology Lab, Department of Biochemistry and Molecular Biology, University of Dhaka, Dhaka 1000, Bangladesh \\ Correspondence should be addressed to Aparna Islam; aparna@bracu.ac.bd
}

Received 22 April 2014; Revised 3 July 2014; Accepted 3 July 2014; Published 26 August 2014

Academic Editor: Xing-Ming Zhao

Copyright ( $) 2014$ Samsad Razzaque et al. This is an open access article distributed under the Creative Commons Attribution License, which permits unrestricted use, distribution, and reproduction in any medium, provided the original work is properly cited.

\begin{abstract}
Microarray datasets are widely used resources to predict and characterize functional entities of the whole genomics. The study initiated here aims to identify overexpressed stress responsive genes using microarray datasets applying in silico approaches. The target also extended to build a protein-protein interaction model of regulatory genes with their upstream and downstream connection in Arabidopsis thaliana. Four microarray datasets generated treating abiotic stresses like salinity, cold, drought, and abscisic acid (ABA) were chosen. Retrieved datasets were firstly filtered based on their expression comparing to control. Filtered datasets were then used to create an expression hub. Extensive literature mining helped to identify the regulatory molecules from the expression hub. The study brought out 42 genes/TF/enzymes as the role player during abiotic stress response. Further bioinformatics study and also literature mining revealed that thirty genes from those forty-two were highly correlated in all four datasets and only eight from those thirty genes were determined as highly responsive to the above abiotic stresses. Later their protein-protein interaction (PPI), conserved sequences, protein domains, and GO biasness were studied. Some web based tools and software like String database, Gene Ontology, InterProScan, NCBI BLASTn suite, etc. helped to extend the study arena.
\end{abstract}

\section{Introduction}

Plant stresses are the reasons for food insecurity and thus are a major threat to mankind [1]. Environmental stress is one of the biggest problems which has already been counted as a responsible phenomenon for reducing crop yields [2]. The effects of climate change like an increase in global temperatures may lead to drought, and increase in humidity is likely to increase plant susceptibility to pathogens. This has been recorded to be a major source of crop spoilage all over the world [3]. These factors are conspiring to greatly endanger food security, leading to social instability and increased poverty, particularly in developing countries. Clearly, this is not just a problem for the developing world but is a global problem affecting the entire population [4]. It is an utter necessity to understand the mechanisms by which plants adapt to environmental stresses to maintain world food supplies duly.

Plants respond to environmental stresses at both cellular and molecular level by altering the expression of many genes via different types of complex molecular signaling networks [5]. The knowledge of these pathways including identification of the regulatory codes would provide opportunities developing stress tolerance plant production through genetic manipulation. In the postgenomic era, understanding of these cellular systems is becoming increasingly important for biologists. Several methodologies are available $[6,7]$ but the data generated from these methods covers just a few complexes or pathways and is limited to a handful of model organisms. As a result, computational bioinformatics methods have been developed to integrate this data and to extrapolate from it to provide predictions for proteins 
TABLE 1: Microarray datasets collected for this study.

\begin{tabular}{lll}
\hline Serial & Accession & Description of the data \\
\hline 1 & E-MEXP-3714 & $\begin{array}{l}\text { To identify novel miRNA and NAT-siRNAs that are associated with } \\
\text { salt and cold stresses in Arabidopsis, we generated small RNA } \\
\text { sequences from Arabidopsis plants under salt and cold stress } \\
\text { treatments. Sequencing of small RNAs in Arabidopsis under salt and } \\
\text { cold stress conditions. }\end{array}$ \\
\hline 3 & E-GEOD-42290 & $\begin{array}{l}\text { Expression data in an Arabidopsis cytokinin (CK) signaling mutant, } \\
\text { ahp2, 3, } 5 \text { and its wild type plant (Col-0) under drought and } \\
\text { well-water (control) conditions. }\end{array}$ \\
\hline 4 & E-GEOD-45543 & $\begin{array}{l}\text { Microarray analysis of transcriptional responses to abscisic acid and } \\
\text { salt stress in Arabidopsis thaliana }\end{array}$ \\
\hline
\end{tabular}

and organisms not yet experimentally well characterized [8-10].

Various abiotic stresses, such as drought, high salinity, and variable temperature, negatively impact plant growth and productivity. Plants have adapted to respond to these stresses at the molecular, cellular, physiological, and biochemical level, enabling them to survive. Various adverse environmental stresses induce the expression of a variety of genes in many plant species [11, 12]. Numerous stress-induced genes have been identified using microarray experiments $[13,14]$. The products of these genes are thought to promote stress tolerance and to regulate gene expression through signal transduction pathways [11].

In current study, in silico approaches focused on finding the connection between upregulated genes in different abiotic stress conditions. Arabidopsis is one of the model organisms for studying plant genetics and development. The genome of Arabidopsis is the first to be sequenced among higher plants and is believed to comprise at least 30,700 genes. Of these genes, the function of approximately onethird (9194) remains unknown according to the functional Gene Ontology (GO) category listed by the Arabidopsis Information Resource (TAIR) [15]. Of the remainder, a large proportion lack complete or adequate functional annotation. We in the present study aimed at constructing a genome-wide functional network of Arabidopsis by integrating relations extracted from diverse data sources. So, the aim was to construct a genome-wide functional network of Arabidopsis by integrating relations extracted from diverse in silico data sources. The experiment initiated aiming at upregulated genes, TF, and enzymes during four abiotic stresses, like, cold, drought, salinity and responses to abscisic acid.

\section{Materials and Methods}

2.1. Work Plan. The whole working procedure is demonstrated in Figure 1(a). Here, only processed datasets were taken for the study.

2.2. Microarray Datasets Retrieval. In the current study, microarray datasets were retrieved from ArrayExpress database [16] from EMBL-EBI (https://www.ebi.ac.uk/ arrayexpress/). The retrieval was random and the only specification was four different stress signals like salinity, drought, cold, and response to ABA. Only processed datasets were downloaded. The retrieved datasets were generated using at least three replicates. The processed datasets were initiated with at $\sim 15,000$ transcripts. A brief description of the collected data with their ArrayExpress accession has been mentioned in Table 1 .

2.3. Data Filtering. All collected datasets were downloaded and copied in an excel sheet. The target was to create a scatter plot based on the value (log value) generated by the microarray expression. A simple layout was created from the value corresponding to the samples represented in the study.

2.4. Common Pattern Study. Cytoscape version 3.1.0 (http:// www.cytoscape.org/) networking software was used to create an expression hub using the filtered dataset. This program was run with default parameters to import and export data in a variety of formats, from simple delimited text formats to XML and other sophisticated formats for sharing data with other programs [17]. The collected datasets were renamed to have the extension ".pvals" to be recognized by Cytoscape. The data were organized as a matrix, with each row representing the expression results for one gene/protein in the network. The first row provided column labels. The first column holds the gene/protein identifier, while the second column contains expression value. The data also contained $P$ values, so each experiment was represented with two columns: the first is assumed to contain the expression measure, the second contains the significance measure, and the two columns were exactly having the same label.

\subsection{Retrieving Common Upregulated Genes under Four} Stresses. All expressed genes from the physically interacting nodes were put in Venny to find the common genes/proteins, and a Venn diagram was produced as an output file (http://bioinfogp.cnb.csic.es/tools/venny/). The insertions of the data were selective and the datasets were named according to the microarray experiments. 


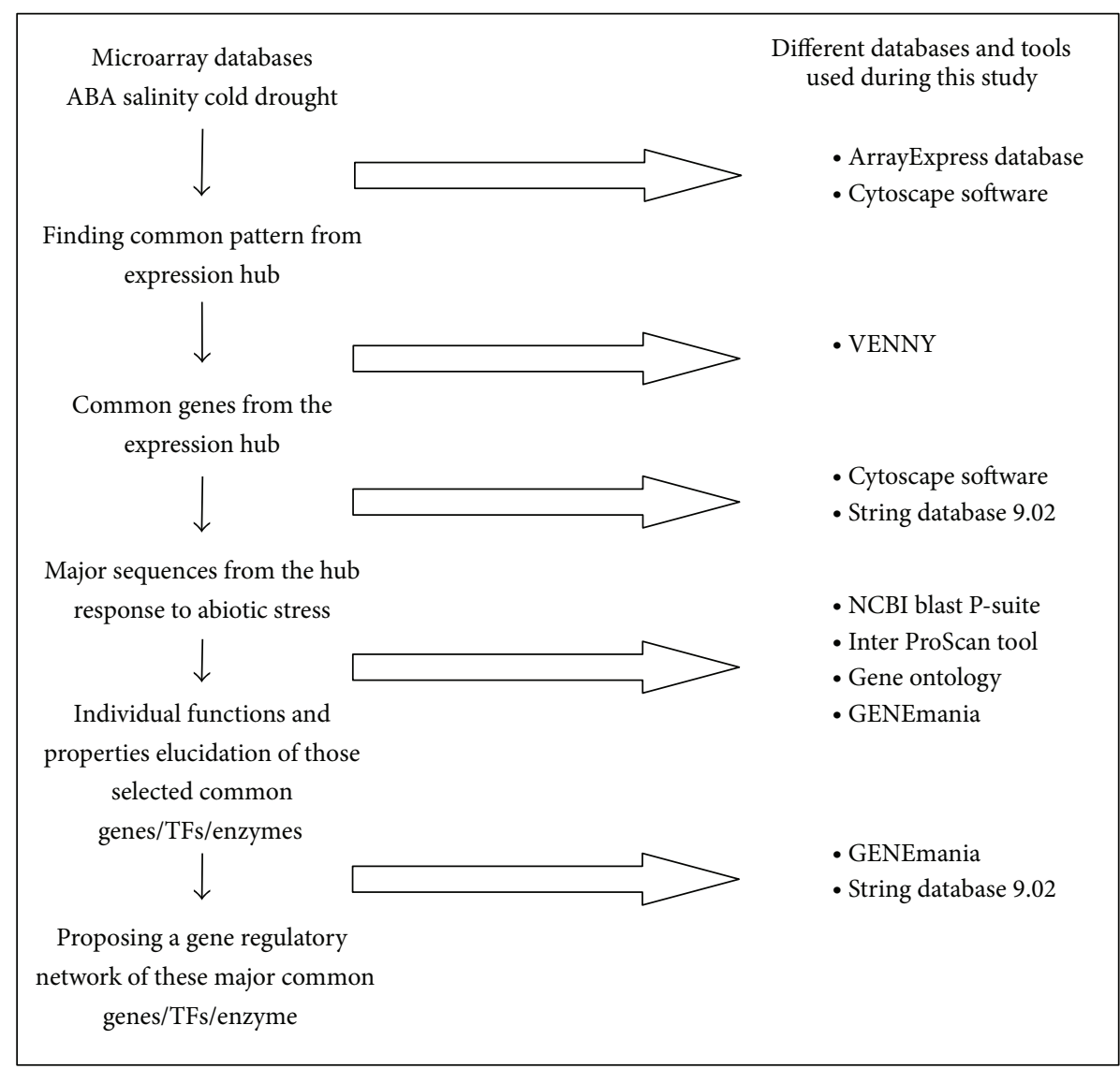

(a)

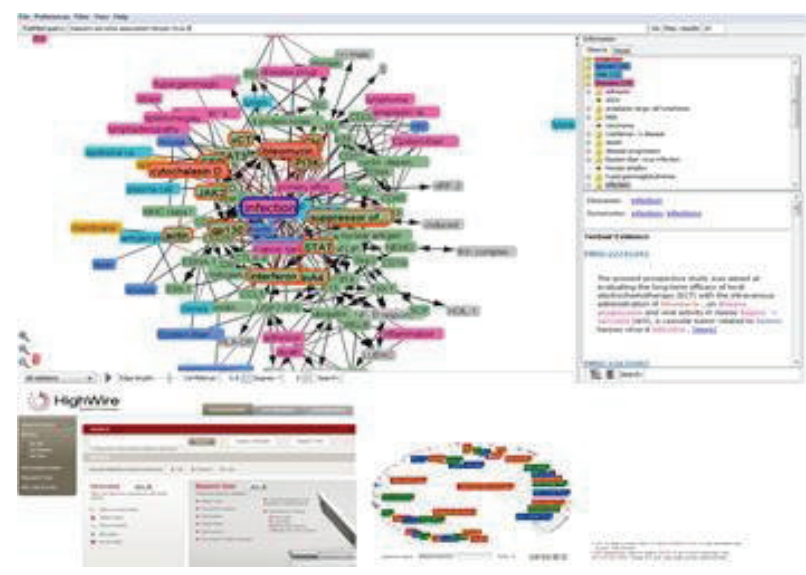

(b)

Figure 1: (a) A schematic diagram elucidating the whole experimental procedures mentioned with all used databases and software. (b) A screen shot of the used tools for literature search. Alibaba and Highwire searching tools were extensively used in this study.

2.6. Protein-Protein Interaction Study. Those commonly upregulated genes were taken for further analysis. Protein-protein interaction was identified using String 9.05 (http://string-db.org/) database [18] and only the validated interactions were considered for later analysis. The interaction network for the target proteins were further validated using Advanced Network Merge plug-in integrated in Cytoscape platform. The integration here was based on functional resembles between the nodes.

2.7. Selection of the Regulatory Proteins/TF/Enzymes. Through extensive text mining and literature search the initial stress related gene pool for stress response 


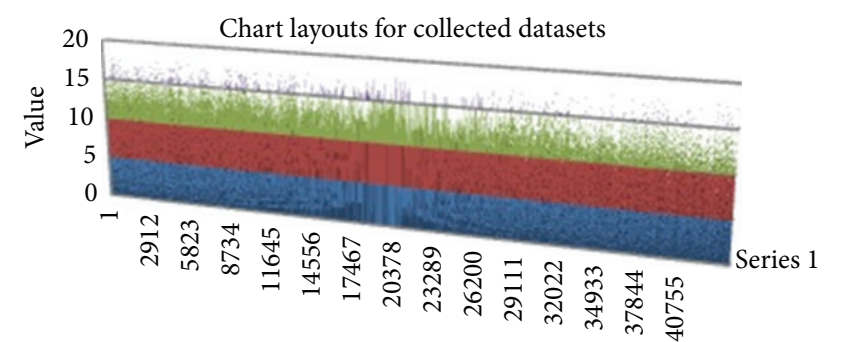

Reporters

15-20 $15-10$

$10-15 \square 0-5$

Figure 2: Chart layouts for collected datasets for this study. The value of the represented transcripts ranged from 0 to 20 and was classified into four distinct groups like $0-5,5-10,10-15$, and 15-20. All transcripts are upregulated at the range of up to 5-10.

was generated. For searching literatures associated with Arabidopsis, the most important collection of scientific publications used was PubMed (http://www.ncbi.nlm nih.gov/pubmed). Other data-mining tools used for literature search were Highwire Topicmap and Alibaba (http://alibaba.informatik.huberlin.de) (Figure 1(b)).

2.8. Target Gene Homolog Identification. Target genes were blasted in BlASTn suite from NCBI (https://blast. ncbi.nlm.nih.gov/Blast.cgi?PROGRAM=blastnPAGETYPE= BlastSearch\&LINK_LOC=blasthome). The BLAST hit was optimized for highly similar sequences (Megablast). The best homolog of the target gene and function were collected for further analysis.

2.9. Gene Ontology (GO) Analysis. Gene ontology program [19] from NCBI was used to find out functional similarities and to calculate the branching pathways by putting each individual as separate input. The output was considered from all three categories (cellular, molecular, and biological process) converted into graphical representation.

2.10. Protein Domain Retrieval. Targeted genes functions were determined by finding actual protein domains using InterProScan [20] from EBI (http://www.ebi.ac.uk/interpro/ ). The conserved domains were analyzed to predict functional variability before or after stress condition or finding the actual mechanism behind expressing these common genes in different abiotic stresses.

2.11. Data Analysis. The robustness of the network was analyzed by checking several different parameters of the network. The statistical probability was counted following the methods mentioned by Zaman et al. [21]. The data was modified as a suitable input file for Gene Cluster 3.0 functional clustering tool. No $\log$ transformation was required for the data as they were deposited as log transformed file in the database. Hierarchical cluster was formed using complete linkage using uncentered correlation matrix. $4 \times 4$ SOM (self-organizing
TABLE 2: Selected numbers of transcripts were chosen for further studies.

\begin{tabular}{lcc}
\hline Serial & Treatment & Number of transcripts \\
\hline 1 & ABA & 643 \\
2 & Drought & 526 \\
3 & Cold & 1023 \\
4 & Salinity & 977 \\
\hline
\end{tabular}

matrix) with 100,000 iterations was used for the cluster analysis. The clustering was finally finished performing a PCA (principle component analysis).

\section{Results and Discussion}

3.1. Arrayed Data Analysis. Primarily four microarray datasets from ArrayExpress database were taken. Samples data were collected and arranged in an excel sheet. The samples expression based on log value was justified and only the values of more than 5 were considered in this study. Figure 2 represents the overall expressed data processed from the microarray datasets.

3.2. Selection of Target Genes. The collected data were further screened based on the expression mentioned in Figure 2. Only upregulated genes that are grouped in 15-20 range in Figure 2 were sorted out. A good number of overexpressed genes, TF and enzymes could be selected following the range mentioned and the exact numbers were shown in Table 2.

3.3. Expression Hub with the Selected Transcripts. The selected transcripts ID were then merged into Cytoscape software and the aim was to create an expression hub based on the physical interaction value as well as maximum expression parameters. The hub generated (Figure 3) here demonstrated the interaction and distance among the targeted transcripts. Here the connection among transcripts made three clusters (Figure 3). Only the cluster at the middle connected with the maximum number of the transcripts and these clusters of transcripts (Figure 3(b)) were taken for further screening.

3.4. Common Genes Found in Different Stress Signals. The commonly expressing (i.e., upregulated) and physically connected genes found in different stress signals were then sorted by using the Van Diagram technique to create a Venn diagram, so that common transcripts could easily be isolated from the transcript chunks. The Venn diagram demonstrated that only 42 commonly upregulated genes were found in the selected datasets (Figure 4).

3.5. Protein-Protein Interaction Study of the Forty-Two Upregulated Transcripts. The 42 commonly upregulated genes (Supplementary File 1, see Supplementary Material available online at http://dx.doi.org/10.1155/2014/896513) were then taken for further studies to see their interaction among themselves in terms of physical interaction, coexpression, literature mining, and so forth. The interaction was generated 


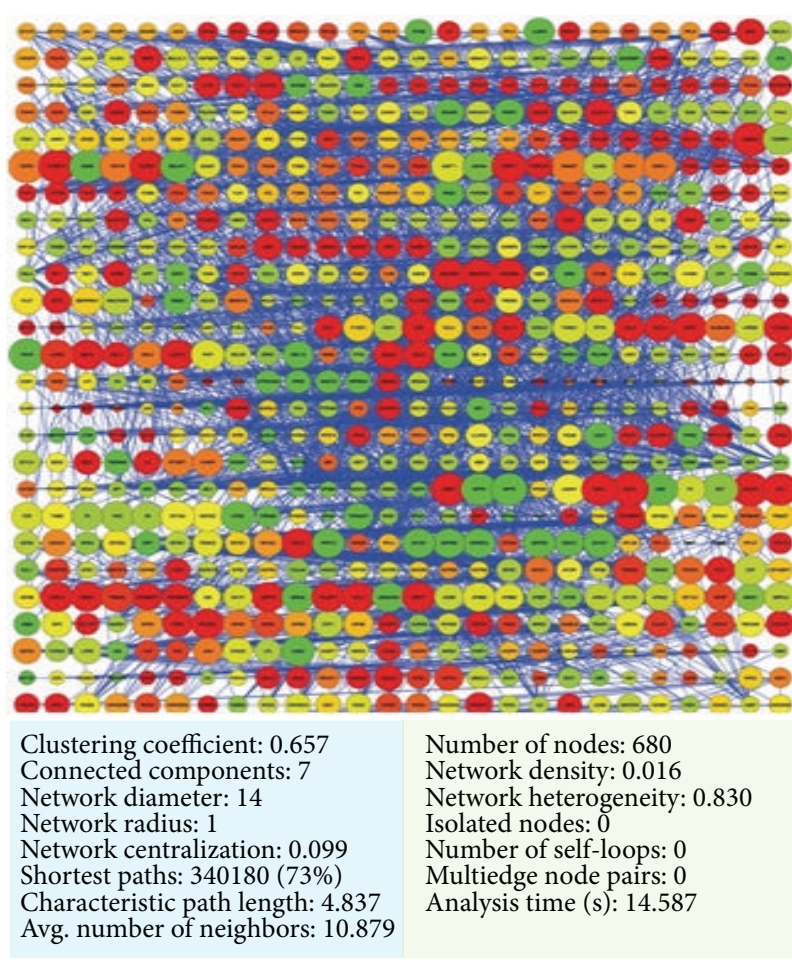

(a)

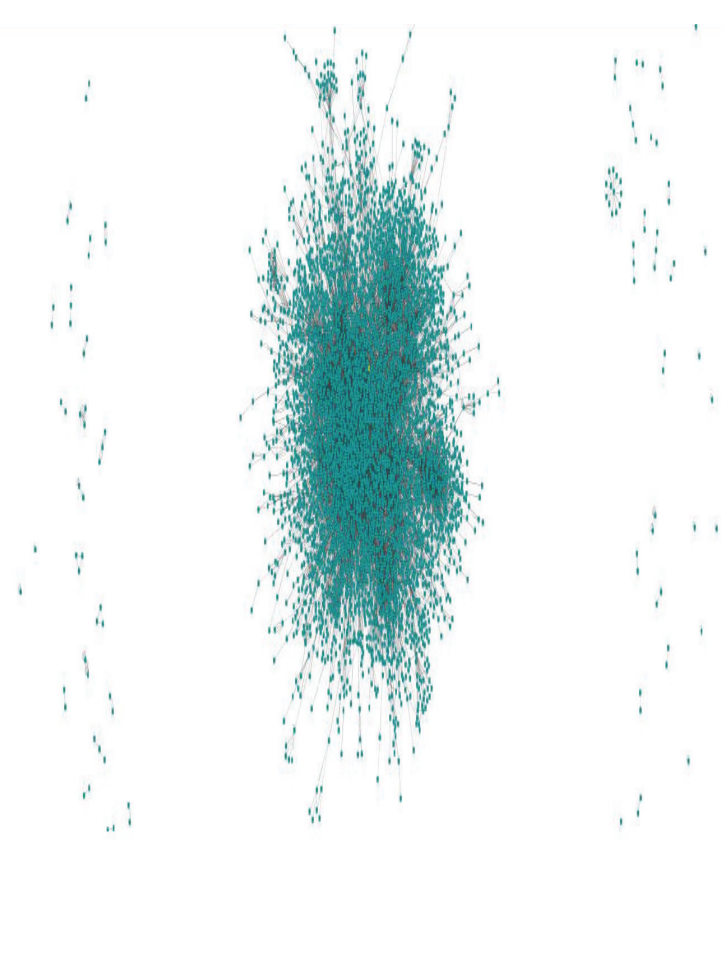

(b)

Figure 3: An expression hub generated by Cytoscape. (a) Here clustering coefficient calculated was 0.657, network diameter was 14 at radius 1, number of nodes were 680, and the network centralization was 0.099. (b) Clustering genes based on physical distance calculated. Three visible clusters were found keeping the coefficient value at 0.5 .

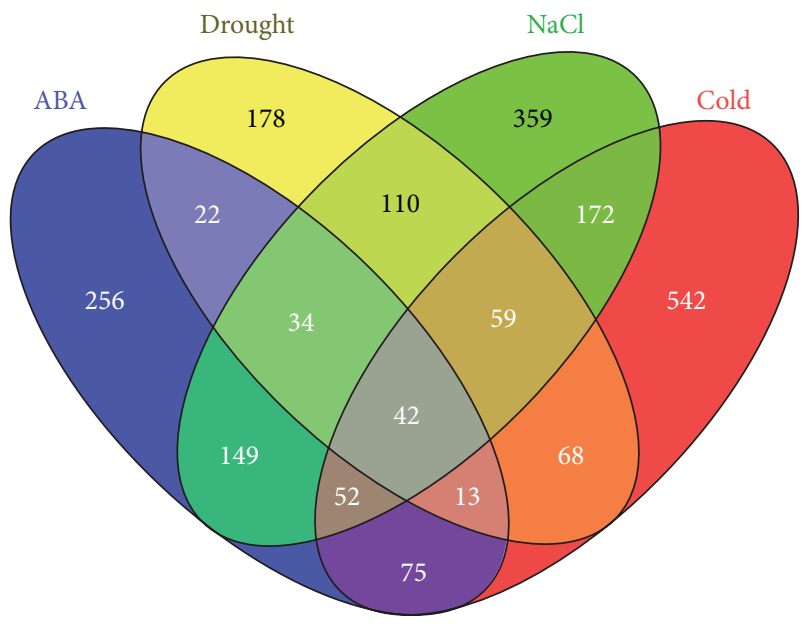

FIGURE 4: A Venn diagram representing the common transcripts from the collected datasets. Note that the four collected datasets were generated from Arabidopsis after salinity, cold, drought, and ABA treatment.

in String Database (version 9.05) and it was found that almost every upregulated gene came in contact with the others and showed a strong corelation. About 30 genes were directly connected while others remain distant in connection (Figure 5). Directly connecting proteins were then brought together to see the interaction (Figure 6) and a strong corelation between transcription factors and antiporter genes and enzymes was observed.

It was revealed that (Figure 5) forty-two upregulated genes are not in a single protein interaction. The database (String 9.05) provided the prediction and the validation of the submitted samples query on the basis of high throughput technique, coexpression and literature mining, and so forth. The forty genes interactions in terms of proteins were checked and only validated interaction was counted for further studies. Only thirty proteins were selected based on validated physical interaction data. Later thirty proteins were submitted into string to get the connection (Figure 6).

3.6. Connectome Genes and Transcription Factor. In the light of the above result eight genes TF and enzymes were bridging among each other and brought their downstream targets in the expression hub. These strongly corelated connectomes in abiotic stress tolerance were short-listed (Table 3) for further studies. It was revealed that only eight major genes, those selected eight major genes (Table 3), were then further analyzed.

In the next section of the result, all possible characters of the targeted eight molecules were revealed depending on their amino acid, protein domains, individual interactomes, and gene ontology to get the whole pictorial view of the genes in three different sectors of life system, biological, molecular, and cellular, respectively. Available free tools mentioned in 


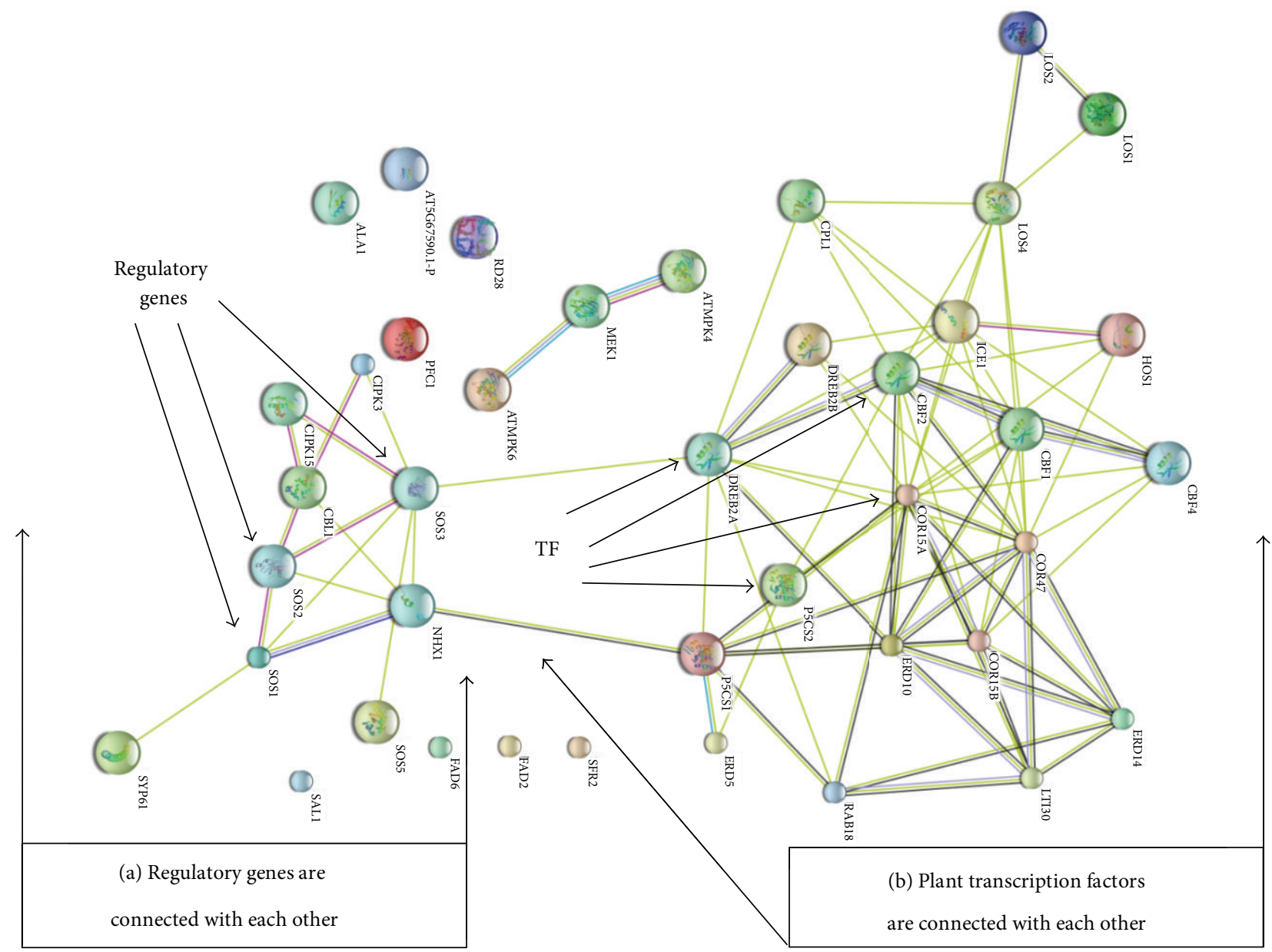

FIGURE 5: Protein-protein interaction networks of plant transcription factors (TFs), enzymes, and regulatory genes in plant abiotic stress responses. Here, regulatory genes and TF are indicated with the arrow mark. Abiotic stresses like drought, salt, cold, and ABA stress factors modulated the level and activity of the regulatory genes and their target genes. The box (b) represents an indication of TF proteins from the model plant Arabidopsis that are connecting with the major regulator of stress responsive genes like SOS1, NHX1, and their targets.

TABLE 3: Selected major eight genes/TF/enzymes with their short form.

\begin{tabular}{lll}
\hline Serial & Gene name & Identity \\
\hline 01 & DREB2A (dehydration-responsive element-binding protein 2A) & Transcription factor \\
02 & P5CS1 (delta-1-pyrroline-5-carboxylate synthase 1) & Enzyme \\
03 & CPL1 (C-terminal domain phosphatase-like 1) & Transcription factor \\
04 & ERD5 (early responsive to dehydration 5) & Transcription factor \\
05 & NHX1 $\left(\mathrm{Na}^{+} / \mathrm{H}^{+}\right.$exchanger) & Vacuolar antiporter \\
06 & SOS1 (salt overly sensitive 1) & Plasma membrane antiporter \\
07 & SOS2 (salt overly sensitive 2) & Protein kinase \\
08 & SOS3 (salt overly sensitive 3) & Calcium-dependent protein serine \\
\hline
\end{tabular}

Section 2 have been extensively applied to get the results to make individual interpretation.

3.7. Conservancy Exploration of the Targeted Genes. Selected eight genes' amino acid sequences were collected from NCBI database and BLASTed in NCBI BLASTp suite using the protein-protein blast algorithm. The conserved domains were retrieved to understand functional entities of the target proteins. Only the homologs close to the search molecule were considered to find out protein superfamily conservancy (Table 4). 


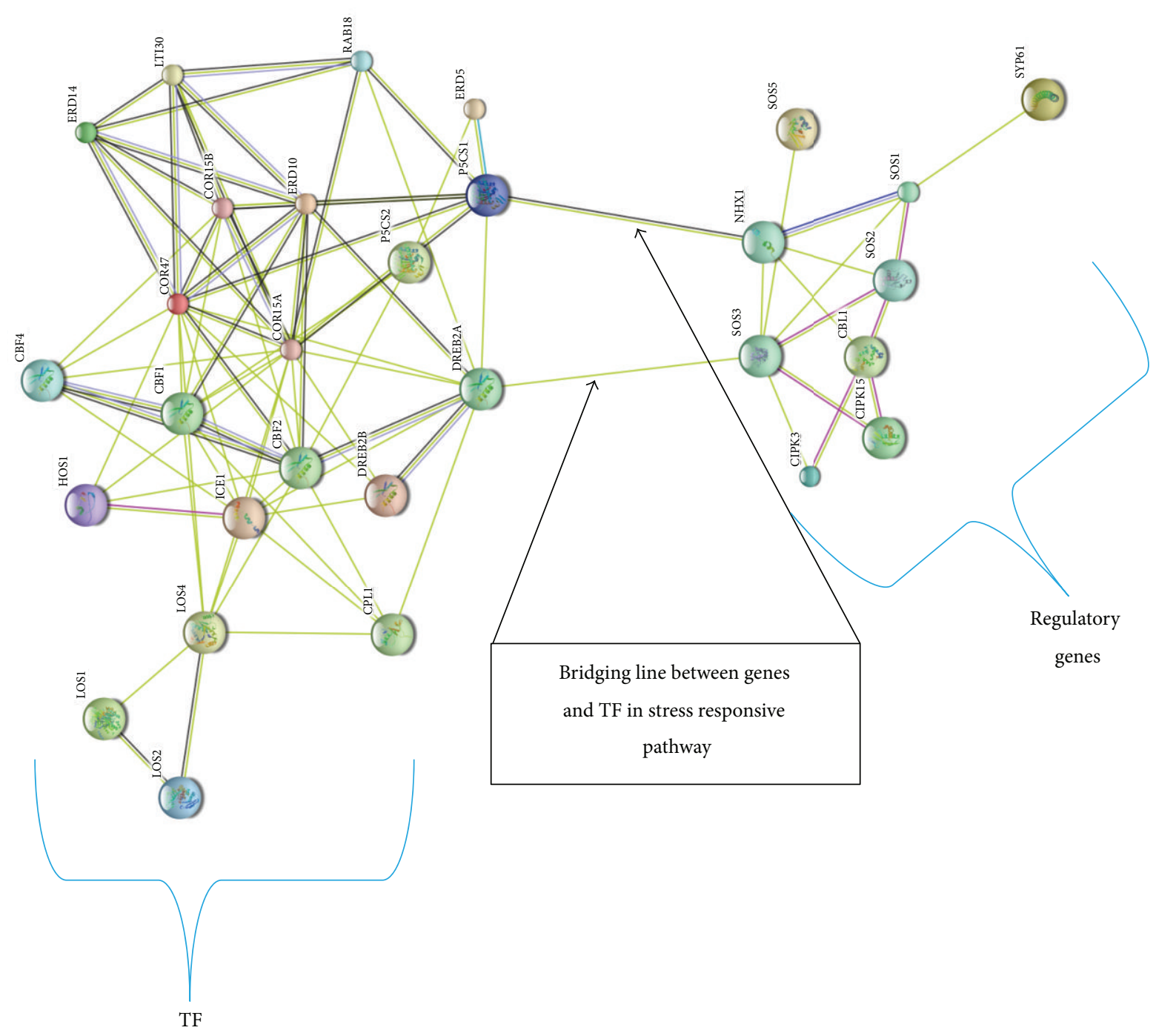

FIGURE 6: A gene regulatory network of thirty commonly upregulated genes in ABA dependent pathway, salinity stress, cold, and drought stress responsive pathways. The bridging between transcription factor and stress responsive proteins clearly indicated their corelation in this figure.

All targeted genes are highly conserved among other species. The mentioned superfamilies (Table 4) are specified in the NCBI database and demonstrated the characterized functions and properties. All of molecules and found superfamily domains have been characterized as a major player on abiotic stress tolerance.

3.8. Functional Domains Retrieval. The protein domains (Table 5) are significantly diverse and bear the importance of each individual protein in stress response in different abiotic stress simultaneously. Only an exchanger domain $\left(\mathrm{Na}^{+} / \mathrm{H}^{+}\right)$ was found to be overrepresented in both NHX1 and SOS1 which demonstrated its functional integrity toward salinity stress. Some kinases are present; their roles have already been explored in upregulating stress responsive genes during stress(es). Interestingly, all these different domains are highly up-regulated in all selected abiotic stresses like cold, salinity, drought and ABA. This correlation helps to hypothesize those single candidate genes, TF and enzymes have different roles in different stress signals.

3.9. Protein-Protein Interaction of the Targeted Eight Genes. Protein-protein interaction was observed using string 9.05 database. Each target molecule based PPI was checked. The PPI interaction and stringency to each other was calculated (Figure 7). All of the proteins interact mostly with stress responsive genes and TF. The calculations showed (Supplementary File 2) that each targeted protein brings more stress responsive molecules into a single string so that they can provide tolerance. Moreover, very specific protein like $N H X 1$ also connects with some 


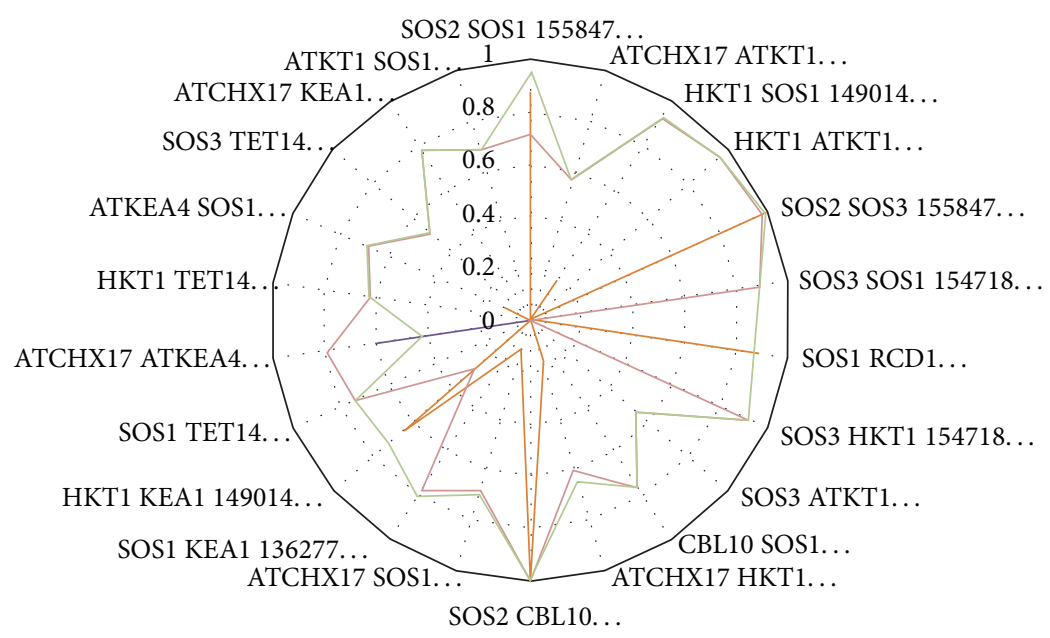

(a)

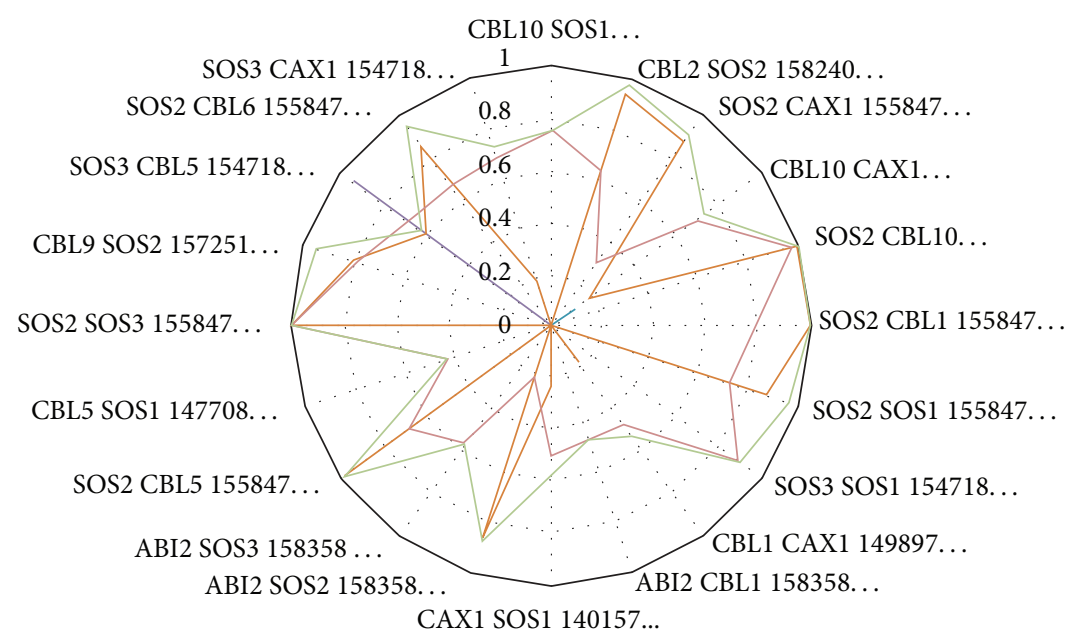

(b)

FIGURE 7: Distance and physical interaction calculated of the targeted genes with their interacting protein.

cold responsive and drought response elements which clarified its functional activity during targeted abiotic stress response.

3.10. Parameters for the Integrated Network. The parameters revealed the robustness of the network. Targeted all upregulated proteins could build up a protein-protein interaction network among themselves (Figure 8). Clustering coefficient of thenetwork is 0.62 . Network diameter was 14 units. Network centralization valued 0.094. Shortest path covered $86 \%$ of the proteins. Average number of neighbors for the nodes was 10.35 . Network heterogeneity was 0.868 . The red line fits the line whereas the blue line shows the power law distribution.

3.11. Gene Ontology Study. Gene ontology study helped to get all correlated real and hypothetical functions of the target protein molecules. It depicted (Table 6) basic and stress inductive functions.
3.12. Final Integration of the Targeted Genes in a Single Correlation Image. A correlation image was drawn based on the calculation and analysis provided in Supplementary File 2 to address an internal correlation of these eight protein molecules in Arabidopsis (Figure 9).

In model plant, Arabidopsis thaliana, thousands of genes have been identified to play different roles in different responses (tolerance and susceptibility). Naika and his colleagues [22] did a similar study with Arabidopsis on stress responses. They compiled a dataset on abiotic stress responses and used functional enrichment analyses like GO (Gene Ontology) and PO (Plant Ontology) annotation to understand plant specific features associated with differential upregulation of genes for individual signals. They have also used STRING to derive interactome and to predicate proteinprotein interaction like the present study using stress responsive transcription factors database (STIFDB), PubMed, and Gene Expression Omnibus (GEO). They found 3091 genes differentially upregulated during 14 different abiotic stresses, namely, abscisic acid, aluminum, cold, cold-drought-salt, 


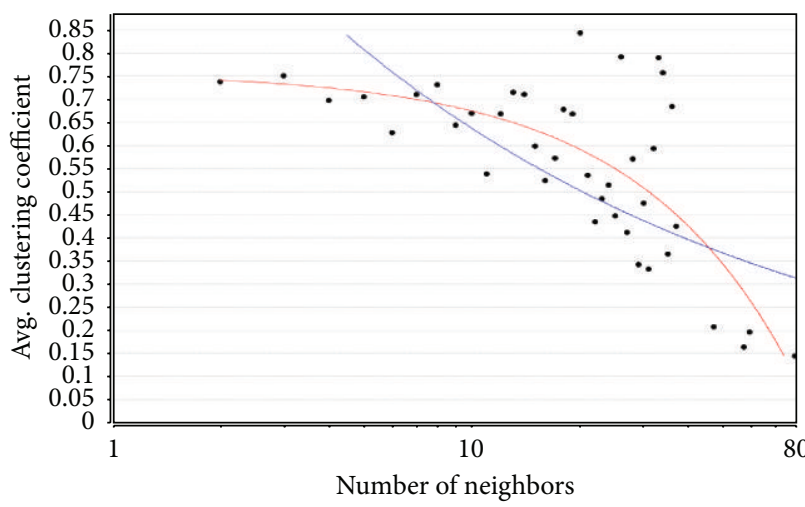

(a)

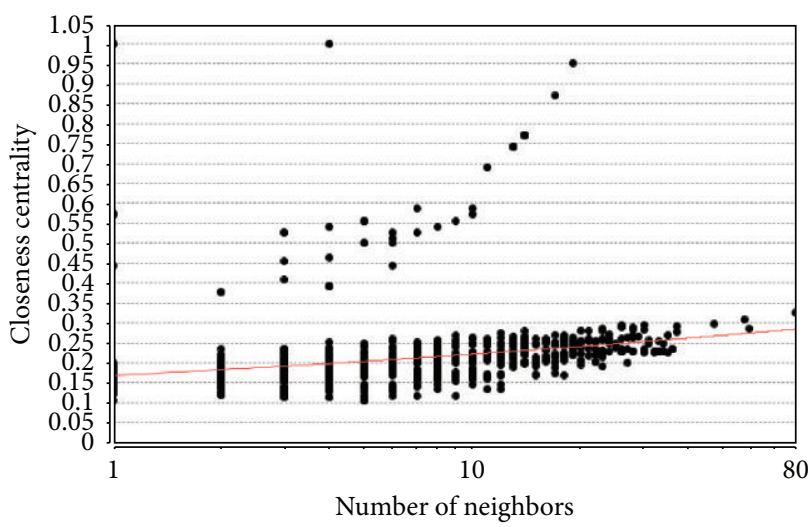

(c)

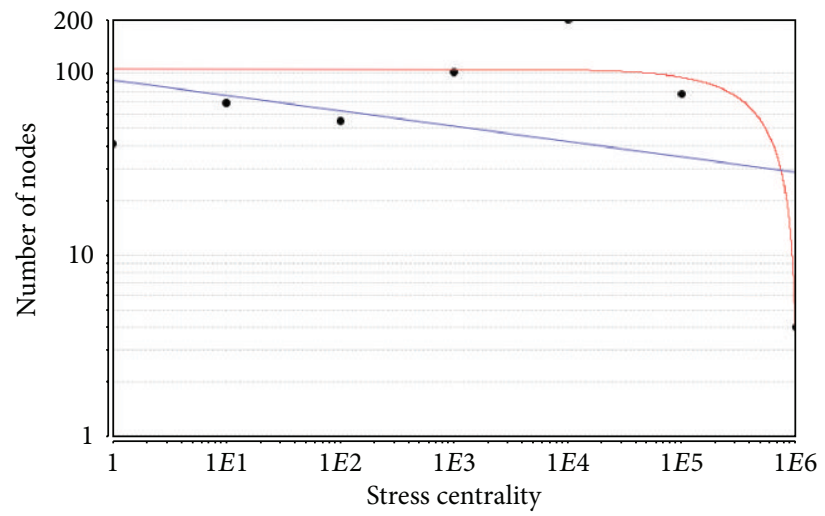

(e)

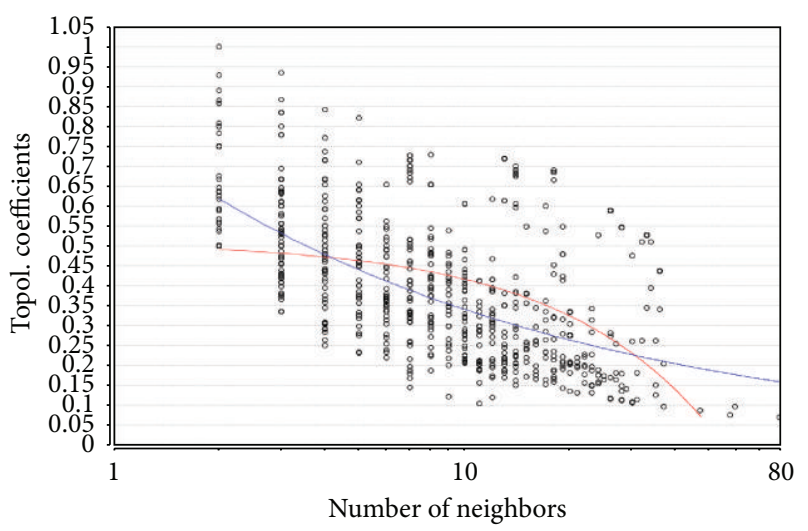

(g)

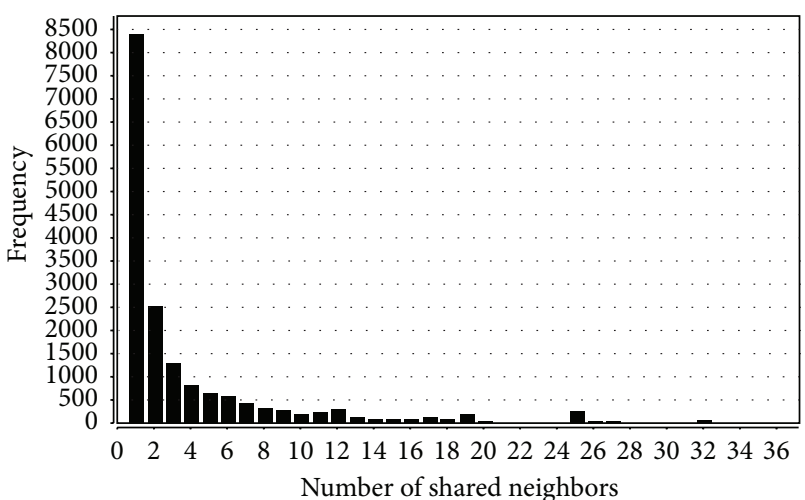

(b)

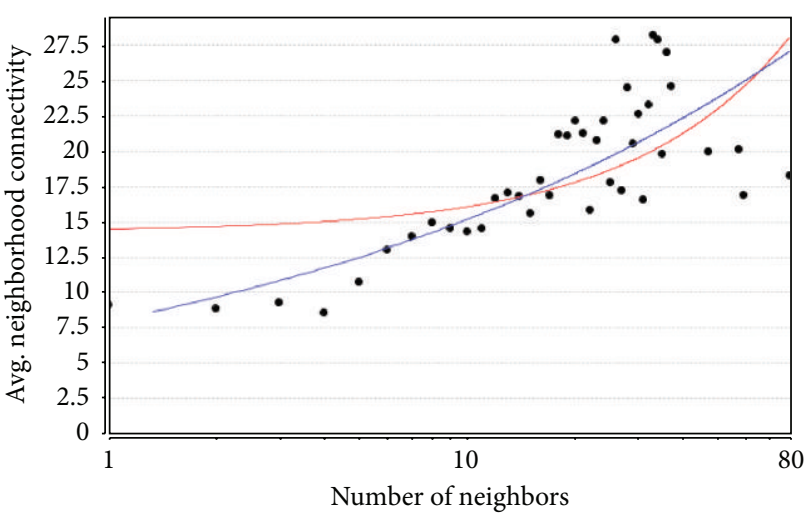

(d)

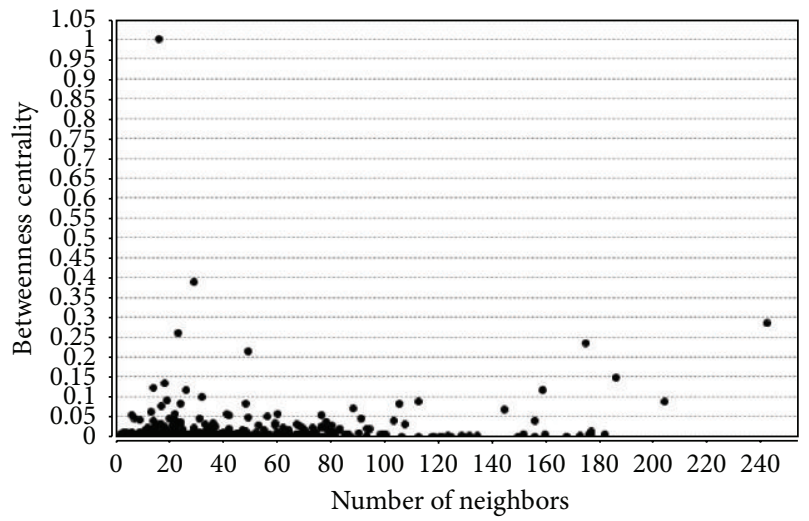

(f)

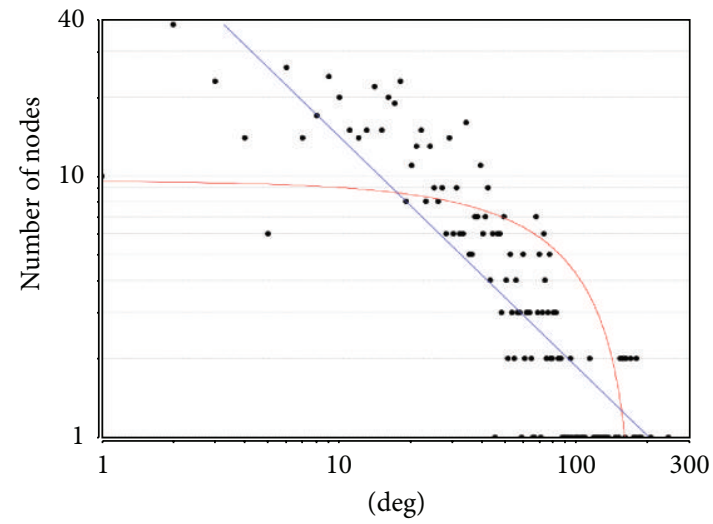

(h)

Figure 8: Continued. 


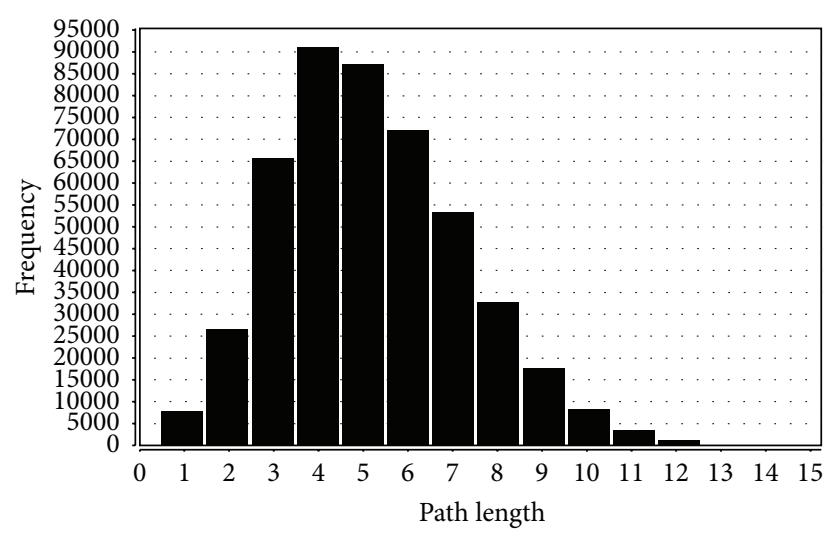

(i)

FIGURE 8: Parameters for the integrated network. (a) Average clustering coefficient versus number of neighbors, (b) betweenness centrality versus number of neighbors, (c) closeness centrality versus number of neighbors, (d) average neighborhood connectivity versus number of neighbors, (e) number of nodes versus degree, (f) frequency versus number of shared neighbors, (g) frequency versus path length, (h) number of nodes versus stress centrality, and (i) topological coefficient versus number of neighbors have been plotted.

TABLE 4: Targeted proteins and their conserved domains search by protein-protein blast algorithm. Homologs of the target proteins with their coverage and identities indicated the conservancy of the targeted protein among species.

\begin{tabular}{|c|c|c|c|c|c|}
\hline Serial & Name & Conserved domain & Homologs & Identity (I) and Coverage (C) & Functions of homologs \\
\hline 1 & DREB2A & AP2 superfamily & Arachis hypogaea & C: $100 \%$, I: $99 \%$ & Drought responsive elements \\
\hline 2 & P5CS1 & $\begin{array}{l}\text { AAK } \\
\text { superfamily/ALDH-SF } \\
\text { superfamily }\end{array}$ & Brassica napus & C: $100 \%$, I: $97 \%$ & $\begin{array}{l}\text { Encodes a } \\
\text { delta-1-pyrroline-5-carboxylate } \\
\text { synthase and responsive to } \\
\text { abiotic stress tolerance }\end{array}$ \\
\hline 3 & CPL1 & $\begin{array}{l}\text { NIF superfamily/DSRM } \\
\text { superfamily }\end{array}$ & Theobroma cacao & C: $99 \%$, I: $63 \%$ & $\begin{array}{l}\text { Encodes a novel transcriptional } \\
\text { repressor harboring two } \\
\text { double-stranded RNA-binding } \\
\text { domains }\end{array}$ \\
\hline 4 & ERD5 & Pro_dh superfamily & Arabis stelleri & C: $100 \%$, I: $97 \%$ & $\begin{array}{l}\text { Encodes a proline oxidase and is } \\
\text { expressed by high levels of } \\
\text { osmotic stress }\end{array}$ \\
\hline 5 & NHX1 & $\begin{array}{l}\text { TM_PBP1_branched-chain- } \\
\text { AA_like } \\
\text { superfamily }\end{array}$ & Olimarabidopsis pumila & C: $100 \%$, I: $99 \%$ & Vacuolar antiporter \\
\hline 6 & SOS1 & $\begin{array}{l}\text { TM_PBP1_branched-chain- } \\
\text { AA_like } \\
\text { superfamily/CAP_ED } \\
\text { superfamily }\end{array}$ & Boechera stricta & C: $100 \%$, I: $89 \%$ & $\mathrm{Ca}^{+}$responsive elements \\
\hline 7 & SOS2 & $\begin{array}{l}\text { PKc like } \\
\text { superfamily/AAMPKA_C } \\
\text { like superfamily }\end{array}$ & Eutrema salsugineum & C: $100 \%$, I: $92 \%$ & Protein kinase \\
\hline 8 & SOS3 & EFh superfamily & Brassica napus & C: $99 \%, I: 86 \%$ & Membrane transporter \\
\hline
\end{tabular}

dehydration, drought, heat, iron, light, $\mathrm{NaCl}$, osmotic stress, oxidative stress, UV-B, and wounding. In the present study, only four out of the 14 abiotic stress signals, Slat, Cold, Drought, and ABA, were studied. However, Naika and his colleagues [22] kept the upregulated gene group under an ID and did not go further to gene level to find out the specific genes and their specific interaction [22]. But in the present study such interconnectome was done in Arabidopsis thaliana.

The aim of the study was initially to find out commonly upregulated genes in different abiotic stress and by doing that the ultimate goal was to hypothesize a gene regulatory network. In current study, four abiotic stress dependent gene expression counts were taken. The expression hub creations 
TABLE 5: Target proteins and their characterized domains explored using InterProScan.

\begin{tabular}{|c|c|c|}
\hline Serial & Name & Protein domains \\
\hline 1 & DREB2A & $\begin{array}{l}\text { (1) AP2/ERF domain } \\
\text { (2) DNA binding domain } \\
\text { (3) Integrase type }\end{array}$ \\
\hline 2 & P5CS1 & $\begin{array}{l}\text { (1) Gamma-glutamyl phosphate reductase } \\
\text { (2) Aspartate/glutamate/uridylate kinase } \\
\text { (3) Glutamate/acetylglutamate kinase } \\
\text { (4) Glutamate 5-kinase/delta-1-pyroline-5-carboxylate synthase } \\
\text { (5) Delta-1-pyroline-5-carboxylate synthase } \\
\text { (6) Aldehyde dehydrogenase domain } \\
\text { (7) Aldehyde/histidinol dehydrogenase } \\
\text { (8) N-terminal aldehyde dehydrogenase } \\
\text { (9) C-terminal glutamate 5-kinase } \\
\text { (10) Conserved site gamma-glutamyl phosphate reductase GPR }\end{array}$ \\
\hline 3 & CPL1 & $\begin{array}{l}\text { (1) Double-stranded RNA-binding } \\
\text { (2) NLI interacting factor } \\
\text { (3) Double-stranded RNA-binding-like domain } \\
\text { (4) HAD-like domain }\end{array}$ \\
\hline 4 & ERD5 & $\begin{array}{l}\text { (1) Proline dehydrogenase } \\
\text { (2) Proline oxidase }\end{array}$ \\
\hline 5 & NHX1 & $\begin{array}{l}\text { (1) } \mathrm{Na}^{+} / \mathrm{H}^{+} \text {exchanger } \\
\text { (2) } \mathrm{CPA} 1 \text { family }\end{array}$ \\
\hline 6 & SOS1 & $\begin{array}{l}\text { (1) Cyclic nucleotide-binding domain } \\
\text { (2) Cation } / \mathrm{H}^{+} \text {exchanger } \mathrm{Na}^{+} / \mathrm{H}^{+} \text {exchanger } \\
\text { (3) CPA1 family } 4 \text {. } \\
\text { (4) Cyclic nucleotide-binding-like }\end{array}$ \\
\hline 7 & SOS2 & $\begin{array}{l}\text { (1) Protein kinase, catalytic domain } \\
\text { (2) Serine/threonine-/dual specificity protein kinase } \\
\text { (3) NAF domain } \\
\text { (4) Serine/threonine-protein kinase, active site } \\
\text { (5) Protein kinase-like domain } \\
\text { (6) Protein kinase, ATP binding site } \\
\text { (7) NAF/FISL domain } \\
\text { (8) Tyrosine-protein kinase }\end{array}$ \\
\hline 8 & SOS3 & $\begin{array}{l}\text { (1) Recoverin } \\
\text { (2) EF-hand domain } \\
\text { (3) EF-hand-like domain }\end{array}$ \\
\hline
\end{tabular}

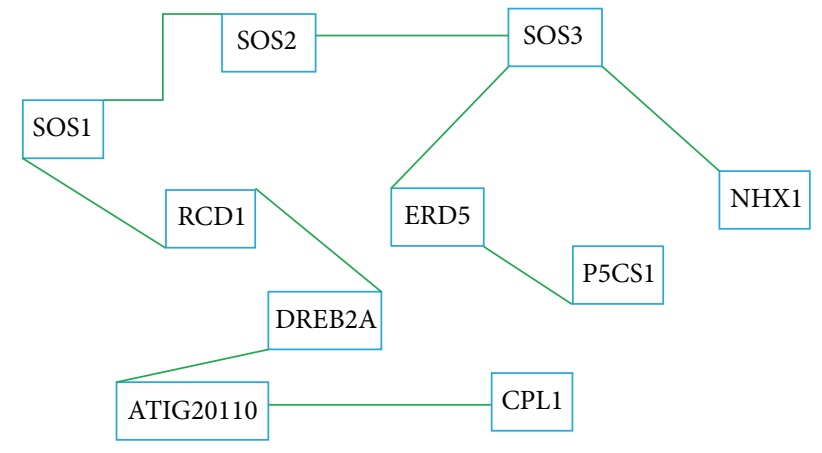

FIGURE 9: Final integration based on the correlation data count (Supplementary File 2).

led to the finding out of the most common genes/proteins that are upregulated in all targeted abiotic stress conditions. Then the sorting was done based on the connectome data and the only bridging molecules were taken for further studies.
Then, extensive bioinformatics tools and databases were used to characterize all individuals in terms of similarities, conservancy, protein domain, GO, and individual interaction. It turned out that all individuals are highly correlated in functions and diverse in mechanism at the same time. Most of the GO annotation referred to functional entities in common patterns which helped to create a regulatory network that depict that these targeted genes/proteins are the most common and role player in plants during stress and maintain some uniqueness. Moreover, most of the functions of these targeted genes/proteins have DNA binding properties which can be a major basis of saying that these molecules are most competent for initiating stress tolerance response as they bring about more TF, enzymes, and/or other regulatory genes in the same string during stress tolerance.

\section{Conclusion}

Bioinformatics study based on online tools and database using freely available microarray datasets show that there 
TABLE 6: GO annotation of the targeted proteins. It shows their diverse and very significant role during stress.

\begin{tabular}{ll}
\hline Name & Direct annotation by GO \\
\hline DREB2A & $\begin{array}{l}\text { Protein binding, response to hydrogen peroxide, regulation of transcription, response to chitin, } \\
\text { sequence-specific DNA binding transcription factor activity, response to heat, response to UV-B, response to } \\
\text { water deprivation, heat acclimation, and response to high light intensity }\end{array}$ \\
\hline P5CS1 & $\begin{array}{l}\text { Response to salt stress, response to abscisic acid, hyperosmotic salinity response, pollen development, root } \\
\text { development, response to water deprivation, proline biosynthetic process, delta-1-pyrroline-5-carboxylate } \\
\text { synthetase activity, response to desiccation, and response to oxidative stress }\end{array}$ \\
\hline CPL1 & $\begin{array}{l}\text { Double-stranded RNA binding, phosphatase activity, response to salt stress, response to wounding, abscisic } \\
\text { acid-activated signaling pathway, negative regulation of transcription, DNA-templated, and phosphoserine } \\
\text { phosphatase activity }\end{array}$ \\
\hline ERD5 & $\begin{array}{l}\text { Glutamate biosynthetic process, response to water deprivation, proline catabolic process, proline dehydrogenase } \\
\text { activity, response to oxidative stress, and defense response to bacterium }\end{array}$ \\
\hline NHX1 & $\begin{array}{l}\text { Protein binding, vacuolar membrane, lithium ion transport, sodium:hydrogen antiporter activity, response to } \\
\text { salt stress, regulation of stomatal closure, sodium ion transmembrane transporter activity, leaf development, } \\
\text { and protein import into peroxisome matrix }\end{array}$ \\
\hline SOS1 & $\begin{array}{l}\text { Protein binding, response to hydrogen peroxide, lithium ion transport, response to salt stress, sodium:hydrogen } \\
\text { antiporter activity, sodium ion transmembrane transport, regulation of reactive oxygen species metabolic } \\
\text { process, response to oxidative stress, and response to reactive oxygen species }\end{array}$ \\
\hline SOS2 & $\begin{array}{l}\text { Protein binding, response to salt stress, protein kinase activity, plasma membrane, kinase activity, plant-type } \\
\text { vacuole membrane, and identical protein binding }\end{array}$ \\
\hline SOS3 & $\begin{array}{l}\text { Protein binding, detection of calcium ion, calcium-mediated signaling, cellular potassium ion homeostasis, } \\
\text { stomatal movement, calcium ion binding, calcium-dependent protein serine/threonine phosphatase activity, } \\
\text { and hypotonic salinity response }\end{array}$ \\
\hline
\end{tabular}

are some common genes upregulated during various environmental stresses. The proposed protein-protein interaction network may solve the mystery relating abiotic stress tolerance mechanism, so further validation by wet lab experiments are required to resolve the secret. So, in future attempts need to be taken in the wet bench to analyze their activity in total to have an in-depth idea of their actual activity under stress condition so that it could bring some answers to the farmers in the crop sector as well as in the nature.

\section{Conflict of Interests}

The authors declare that there is no conflict of interests regarding the publication of this paper.

\section{Acknowledgment}

The authors would like to thank BAS-USDA PALS program for funding the project.

\section{References}

[1] M. Jewell, B. Campbell, and C. Bradley, "Transgenic plants for abiotic stress resistance," in Transgenic Crop Plants, C. Kole, C. Michler, A. Abbott, and T. Hall, Eds., pp. 67-132, Springer, Berlin, Germany, 2010.

[2] S. S. Hussain, H. Raza, I. Afzal, and M. A. Kayani, "Transgenic plants for abiotic stress tolerance: current status," Archives of Agronomy and Soil Science, vol. 58, no. 7, pp. 693-721, 2012.

[3] D. S. Battisti and R. L. Naylor, "Historical warnings of future food insecurity with unprecedented seasonal heat," Science, vol. 323, no. 5911, pp. 240-244, 2009.
[4] P. Ronald, "Plant genetics, sustainable agriculture and global food security," Genetics, vol. 188, no. 1, pp. 11-20, 2011.

[5] B. A. Akpinar, B. Avsar, S. J. Lucas, and H. Budak, "Plant abiotic stress signaling," Plant Signaling \& Behavior, vol. 7, no. 11, pp. 1450-1455, 2012.

[6] N. Bhalla and A. F. Dernburg, "A conserved checkpoint monitors meiotic chromosome synapsis in Caenorhabditis elegans," Science, vol. 310, no. 5754, pp. 1683-1686, 2005.

[7] D. Subo, A. Udalski, A. Gould et al., "First space-based microlens parallax measurement: spitzer observations of OGLE-2005-SMC-001," The Astrophysical Journal Letters, vol. 664, no. 2, pp. 862-878, 2007.

[8] S. V. Date and E. M. Marcotte, "Discovery of uncharacterized cellular systems by genome-wide analysis of functional linkages," Nature Biotechnology, vol. 21, no. 9, pp. 1055-1062, 2003.

[9] A. W. Strong, "Maximum Entropy imaging with INTEGRAL/SPI data," Astronomy and Astrophysics, vol. 411, no. 1, pp. L127-L129, 2003.

[10] C. S. Yu, C. J. Lin, and J. K. Hwang, "Predicting subcellular localization of proteins for Gram-negative bacteria by support vector machines based on n-peptide compositions," Protein Science, vol. 13, no. 5, pp. 1402-1406, 2004.

[11] L. Xiong, K. S. Schumaker, and J. Zhu, "Cell signaling during cold, drought, and salt stress," Plant Cell, vol. 14, pp. S165-S183, 2002.

[12] D. Bartels and R. Sunkar, "Drought and salt tolerance in plants," Critical Reviews in Plant Sciences, vol. 24, no. 1, pp. 23-58, 2005.

[13] J. A. Kreps, Y. Wu, H.-S. Chang, T. Zhu, X. Wang, and J. F. Harper, "Transcriptome changes for Arabidopsis in response to salt, osmotic, and cold stress," Plant Physiology, vol. 130, no. 4, pp. 2129-2141, 2002.

[14] M. Seki, J. Ishida, M. Narusaka et al., "Monitoring the expression pattern of around 7,000 Arabidopsis genes under ABA 
treatments using a full-length cDNA microarray," Functional and Integrative Genomics, vol. 2, no. 6, pp. 282-291, 2002.

[15] J. Li, X. Li, H. Su, H. Chen, and D. W. Galbraith, "A framework of integrating gene relations from heterogeneous data sources: an experiment on Arabidopsis thaliana," Bioinformatics, vol. 22, no. 16, pp. 2037-2043, 2006.

[16] G. Rustici, N. Kolesnikov, M. Brandizi et al., "ArrayExpress update-trends in database growth and links to data analysis tools," Nucleic Acids Research, vol. 41, no. 1, pp. D987-D990, 2013.

[17] M. S. Cline, M. Smoot, E. Cerami et al., "Integration of biological networks and gene expression data using Cytoscape," Nature protocols, vol. 2, no. 10, pp. 2366-2382, 2007.

[18] D. Szklarczyk, A. Franceschini, M. Kuhn et al., "The STRING database in 2011: functional interaction networks of proteins, globally integrated and scored," Nucleic Acids Research, vol. 39, no. 1, pp. D561-D568, 2011.

[19] M. Ashburner, C. A. Ball, J. A. Blake et al., "Gene ontology: tool for the unification of biology," Nature Genetics, vol. 25, no. 1, pp. 25-29, 2000.

[20] S. Hunter, P. Jones, A. Mitchell et al., "InterPro in 2011: new developments in the family and domain prediction database," Nucleic Acids Research, vol. 40, no. 1, pp. D306-D312, 2012 (Norwegian).

[21] A. Zaman, M. H. Rahaman, and S. Razzaque, "Kaposi’s sarcoma: a computational approach through protein-protein interaction and gene regulatory networks analysis," Virus Genes, vol. 46, no. 2, pp. 242-254, 2013.

[22] M. Naika, K. Shameer, and R. Sowdhamini, "Comparative analyses of stress-responsive genes in Arabidopsis thaliana: insight from genomic data mining, functional enrichment, pathway analysis and phenomics," Molecular BioSystems, vol. 9, no. 7, pp. 1888-1908, 2013. 

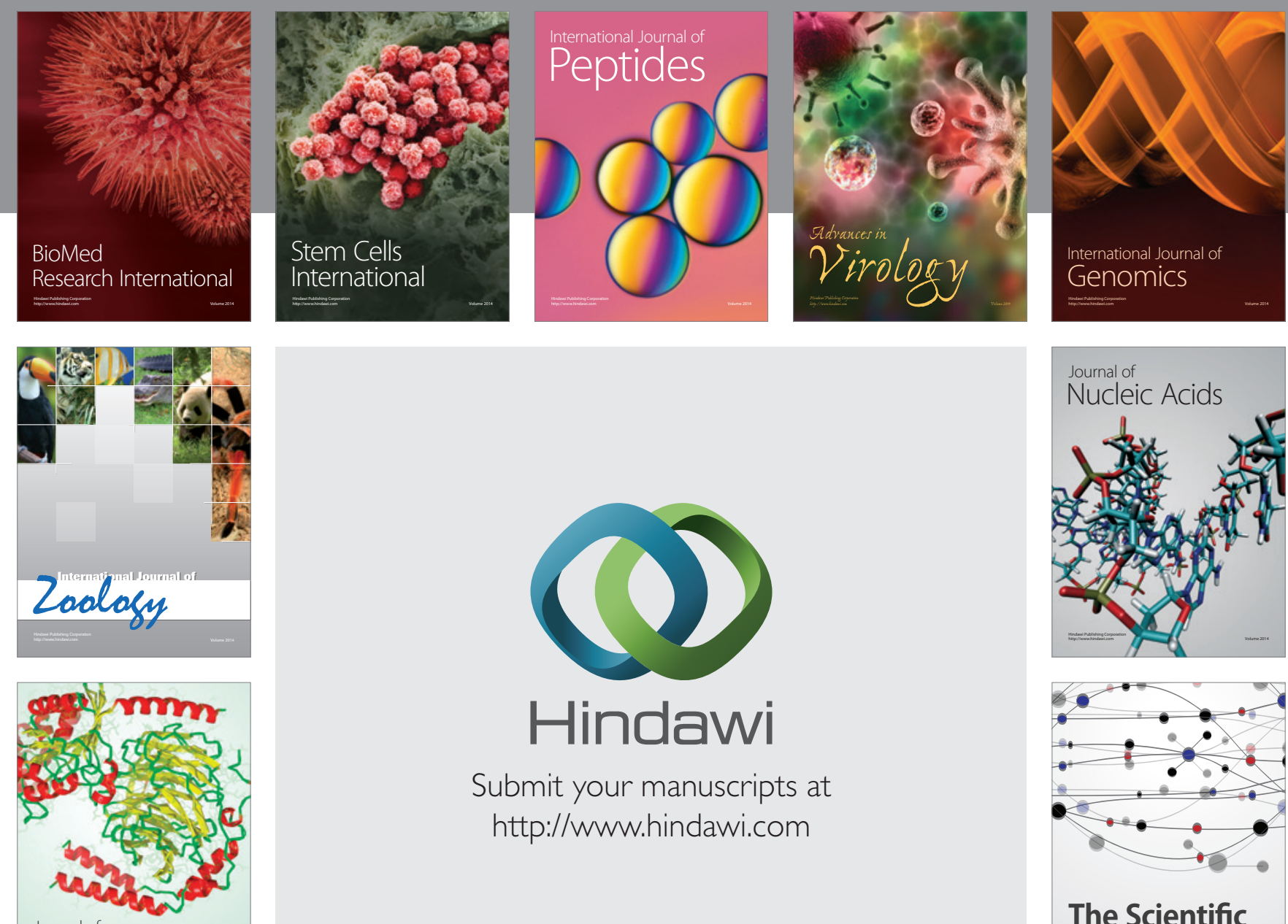

Submit your manuscripts at

http://www.hindawi.com

Journal of
Signal Transduction
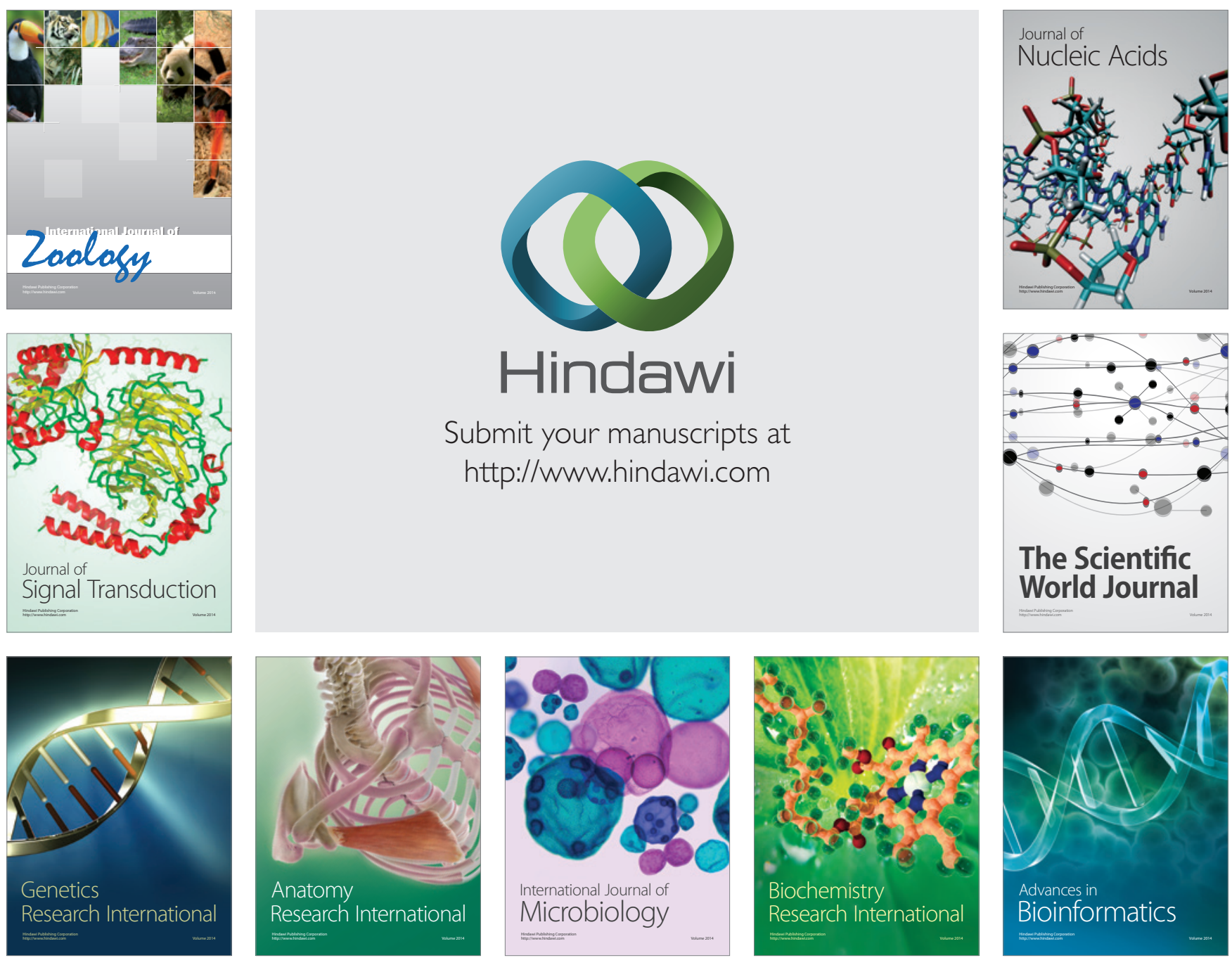

The Scientific World Journal
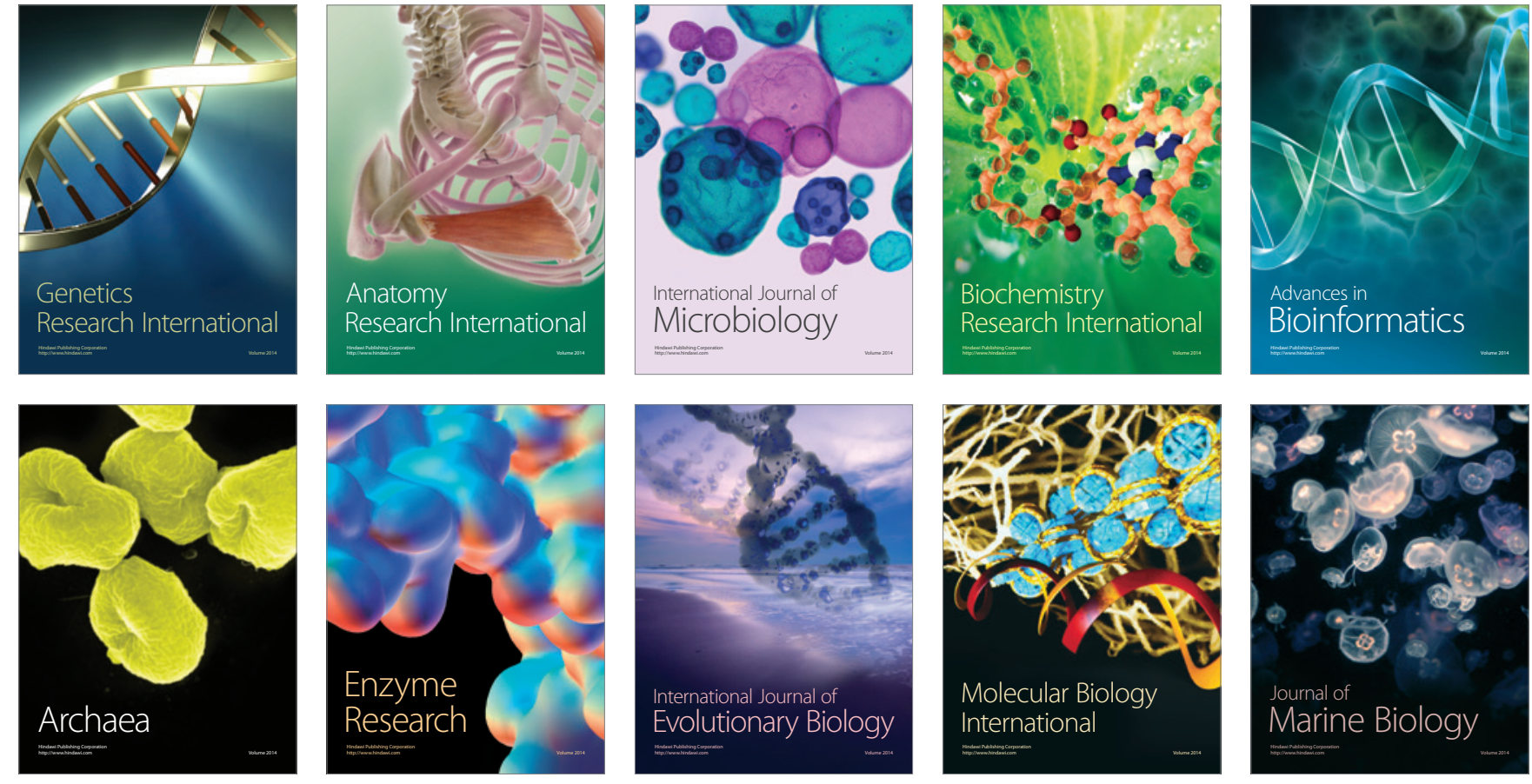